\title{
AMAZÓNAS
}

DOI: https://doi.org/10.34069/RA/2021.7.01

Volumen 4, Número 7/enero-junio 2021

\section{Incendios forestales un factor influyente en la degradación de la biodiversidad del cantón Chilla, Ecuador}

\section{Forest fires an influential factor in the degradation of biodiversity in Chilla canton, Ecuador}

\section{Os incêndios florestais são um fator influente na degradação da biodiversidade no cantão de Chilla, Equador}

Recibido: 15 de enero de $2021 \quad$ Aceptado: 25 de febrero de 2021

\author{
Jonathan Bladimir Zhiminaicela Cabrera ${ }^{1}$ \\ Kevin Andres Lima Morales ${ }^{2}$ \\ José Nicasio Quevedo Guerrero ${ }^{3}$ \\ Rigoberto Miguel García Batista ${ }^{4}$ \\ Bolívar Andres Rogel Jarrín 5
}

\section{Resumen}

A nivel mundial existe una perdida creciente de la biodiversidad, debido a desastres naturales y la actividad antropogénica. Uno de los determinantes de esta degradación son los incendios forestales, que se agudizan especialmente en la estación seca o verano, en las zonas costeras, pero con mayor incidencia en las zonas andinas, donde se dificulta el acceso para el control del fuego. En este estudio se utilizó información bibliográfica y el uso de herramientas como la teledetección para evaluar las afectaciones producidas a la biodiversidad del cantón Chilla, provincia de El OroEcuador, lo que permitió formular una herramienta para proponer medidas de mitigación y restauración de estas zonas de alta vulnerabilidad. Para ello, se usaron dos índices espectrales NBRI y NDVI, calculados por medio de los valores espectrales obtenida del sensor remoto Landsat 8 , con los cuales se pudo mapear las afectaciones producidas por incendios forestales en esta región en el año 2020. Demostrando una mayor eficiencia para tal fin el índice NBRI con respecto al NDVI. Los daños producidos a la biodiversidad incluyeron la perdida de los habitas de especies, degradación forestal, pastizales, suelos, agrobiodiversidad y daños en la cobertura vegetal de la zona.

Palabras clave: incendios forestales, deforestación, degradación forestal, índices espectrales.

\footnotetext{
${ }^{1}$ Carrera de Agronomía, Universidad Técnica de Machala, Facultad de Ciencias Agropecuarias, Semillero de investigación en Recursos Fitogeneticos, Machala, El Oro, Ecuador. https://orcid.org/0000-0001-9462-9608

${ }^{2}$ Carrera de Agronomía, Universidad Técnica de Machala, Facultad de Ciencias Agropecuarias, Grupo de Investigación en Agrobiología de plantas, Machala, El Oro, Ecuador. https://orcid.org/0000-0003-2355-3604

3 MSc. Docente-Investigador, Master en Recursos Fitogeneticos, Universidad Técnica de Machala, Facultad de Ciencias Agropecuarias, Grupo de Investigación en Producción de Alimentos y Sanidad Animal, Machala, El Oro, Ecuador. https://orcid.org/0000-0002-8974-5628

${ }^{4} \mathrm{PhD}$. Docente-Investigador, Doctor en Ciencias Agrícolas, Universidad Técnica de Machala, Facultad de Ciencias Agropecuarias, Grupo de investigación en Agrobiología de plantas, Machala, El Oro, Ecuador. https://orcid.org/0000-0003-2403-0135

${ }^{5}$ Carrera de Agronomía, Universidad Técnica de Machala, Facultad de Ciencias Agropecuarias, Machala, El Oro, Ecuador. https://orcid.org/0000-0002-4641-0086
} 


\title{
AMAZÓNAS
}

\begin{abstract}
Globally, there is a growing loss of biodiversity due to natural disasters and anthropogenic activity. One of the determinants of this degradation is forest fires, which are especially acute in the dry season or summer, in coastal areas, but with greater incidence in the Andean areas, where access for fire control is difficult. In this study, bibliographic information and the use of tools such as remote sensing was used to evaluate the effects produced on the biodiversity of the Chilla canton, province of El Oro-Ecuador, which made it possible to formulate a tool to propose mitigation and restoration measures for these highly vulnerable areas. For this, two spectral indices NBRI and NDVI were used, calculated by means of the spectral values obtained from the Landsat 8 remote sensor, with which it was possible to map the effects produced by forest fires in this region in the year 2020. The NBRI index proved to be more efficient for this purpose than the NDVI. Damage to biodiversity included the loss of species habitats, forest degradation, grasslands, soils, agrobiodiversity and damage to the vegetation cover of the area.
\end{abstract}

Keywords: forest fires, deforestation, forest degradation, spectral indices.

\section{Resumo}

Globalmente há uma perda crescente da biodiversidade devido a desastres naturais e atividades antropogênicas. Um dos determinantes desta degradação são os incêndios florestais, que são especialmente agudos na estação seca ou no verão, em áreas costeiras, mas com maior incidência nas áreas andinas, onde o acesso para controle de incêndios é difícil. Neste estudo, foram utilizadas informações bibliográficas e o uso de ferramentas como o sensoriamento remoto para avaliar os efeitos produzidos na biodiversidade do cantão de Chilla, província de El Oro-Equador, o que permitiu a formulação de uma ferramenta para propor medidas de mitigação e restauração para essas áreas altamente vulneráveis. Para isso, foram utilizados dois índices espectrais NBRI e NDVI, calculados através dos valores espectrais obtidos do sensor remoto Landsat 8, com os quais foi possível mapear as afetações produzidas pelos incêndios florestais nesta região no ano de 2020. Demonstrando uma maior eficiência para este fim o índice NBRI com respeito ao NDVI. Os danos causados à biodiversidade incluíram a perda de habitats de espécies, degradação das florestas, pastagens, solos, agrobiodiversidade e danos à cobertura vegetal da área.

Palavras-chave: incêndios florestais, desmatamento, degradação florestal, índices espectrais.

\section{Introducción}

A nivel global se ha degradado la biodiversidad debido a diversos factores naturales y antropogénicos produciendo. Los incendios forestales son un mecanismo de destrucción de los ecosistemas naturales, teniendo estos mayor impacto en verano, donde los factores ambientales permiten la proliferación del incendio debido a que su control tiende a ser deficiente (Rodríguez et al., 2017), donde las sequías (Matailo-Ramirez et al., 2019) y el cambio climático es uno de los principales percusores de esta problemática (Vidal et al., 2013). Una problemática inmediata para el control de estos sucesos es la falta de equipos especialmente en países o sitios donde no se dificulte por las condiciones topográficas, equipos o personal (Castillo et al., 2003). Generando problemas sociales, económicos y ambientales, para las zonas aledañas, el índice de peligro de incendios forestales que produce estos cambios abruptos pueden implicar un gran potencial para la ocurrencia o propagación de los incendios forestales (Pazmiño, 2019).

Los incendios forestales se relacionan con el principio básico de combustión en el cual la temperatura y el cambio climático influyen directamente en el desarrollo de un incendio. Las condiciones climáticas son idóneas para la proliferación de un incendio, generando grandes pérdidas para la biodiversidad de una región (Flannigan et al., 2000). Anualmente la biodiversidad 
de los bosques forestales y la cobertura vegetal, principal regulador climático, del Ecuador está siendo reducido como consecuencia de la recurrencia de los incendios forestales (Pazmiño, 2019), especialmente en la región Andina, generando así la pérdida de extensas hectáreas de bosques. Evaluar los daños producidos y estimación del área de recuperación son de vital importancia para proponer medidas de mitigación y evitar la reincidencia en las áreas afectadas. En el cantón Chilla su población ha tendido a migrar a las ciudades grandes en busca de otras alternativas para mejorar su economía (Belduma \& Barrezueta-Unda, 2018) desvalorizando el potencial para realizar una explotación sostenible de la alta biodiversidad de especies vegetales y animales de esta región (Zhiminaicela, Quevedo-Guerrero et al., 2020b).

Los sistemas de información geográfica (SIG) y la teledetección son herramientas que permiten evaluar los daños que producen los incendios durante rangos de tiempos (años) y de manera económica por medio de la información espectral obtenida de los valores calculados por medio de la combinación de bandas satelitales sean de Landsat, Sentinel u otro sensores remotos (Chuvieco et al., 2020). La vegetación es un componente clave para evaluar la biodiversidad dentro de una región geográfica específica, la interacción con el ambiente y el cambio climático, con un enfoque en la conservación del patrimonio forestal, que se ve afectado por la ampliación de la frontera agrícola principalmente cambios del uso de suelo de bosques a pastizales (del Campo Parra-Lara \& Bernal-Toro, 2010). Los índices de vegetación en el campo de la percepción remota, permite conocer la fenología y fragilidad de los ecosistemas existentes, entender cómo se ha manejado la vigilancia de eventos climáticos como las sequías e inundaciones, el monitoreo de áreas verdes, las pérdidas forestales a causa de la deforestación o quema y la administración de áreas protegidas (Martínez et al., 2017).

La importancia del Cantón Chilla en la provincia de El Oro, radica en el uso de los recursos naturales y el turismo como lo resaltan Orellana Salas \& Lalvay Portilla (2018), que señalan que estos están estrechamente relacionados de tal manera que el crecimiento turístico está sujeto o depende de cómo sus habitantes hacen uso de los recursos naturales, siendo con mayor frecuencia el uso de los ríos, plantas comestibles, medicinales y arroyos de los cuales el 54\% de la población realiza un buen manejo, mientras que un $10 \%$ no sabe, y $6 \%$ realizada un mal manejo de los mismo. Además, se ha identificado especies nativas forestales de las cuales se puede aprovechar componentes bioactivos (Zhiminaicela, Quevedo-Guerrero et al., 2020b). Esta investigación implementa el uso de SIG para mapear las afectaciones producidas por los incendios forestales en el cantón Chilla, provincia de El Oro-Ecuador. De los cuales se calcularon dos índices espectrales, el índice de vegetación de diferencia normalizada (NDVI) y el índice de quemado normalizado (NBRI), con el fin de analizar su impacto en la biodiversidad de las zonas afectadas.

\section{Metodología}

La metodología utilizada en la investigación combina las observaciones en campo de las afectaciones que producen los incendios en la vegetación y el geo procesamiento espacial utilizando imágenes satelitales e interpretación de los valores espectrales (Zhiminaicela-Cabrera et al., 2020a), la descripción de los procesos realizados para el procesamiento espacial se describe en la (Figura 1.) .

\section{Área de estudio}

Se evaluó las afectaciones producidas en el cantón Chilla, provincia de El Oro-Ecuador, ubicada en las coordenadas geográficas $3^{\circ} 27^{\prime} 0^{\prime \prime} \mathrm{S}, 79^{\circ} 34^{\prime} 48^{\prime \prime} \mathrm{W}$, el cantón Chilla cuenta con una diversidad de altitudes que van desde los $200 \mathrm{msnm}$, en la desembocadura de la quebrada Carabota con el río Jubones, hasta los $3.610 \mathrm{msnm}$, en el cerro Chilola, la cabecera cantonal está ubicada a los $2.429 \mathrm{msnm}$ (Vidal et al., 2015). Cantón con potencial turístico y económico por 


\section{AMAZđ̛́NAS}

sus recursos naturales (Orellana \& Lalvay, 2018) y cultural (Orellana Salas \& Lalvay Portilla, 2018).

\section{Software}

El estudio se llevó a cabo con la utilización del software RStudio, gestor del lenguaje de programación $\mathrm{R}$ versión 4.0.2., debido a que $\mathrm{R}$ cuenta con una amplia gama de disciplinas para recopilar datos, realizar análisis estadísticos y geo procesamiento de información espacial (Gandrud, 2018). Para el estudio se utilizó el software R y como modulador el software RStudio. El sistema utilizado y sus herramientas de procesamiento facilitan la reproducción de las investigaciones.

\section{Diagrama de flujo de la metodología}

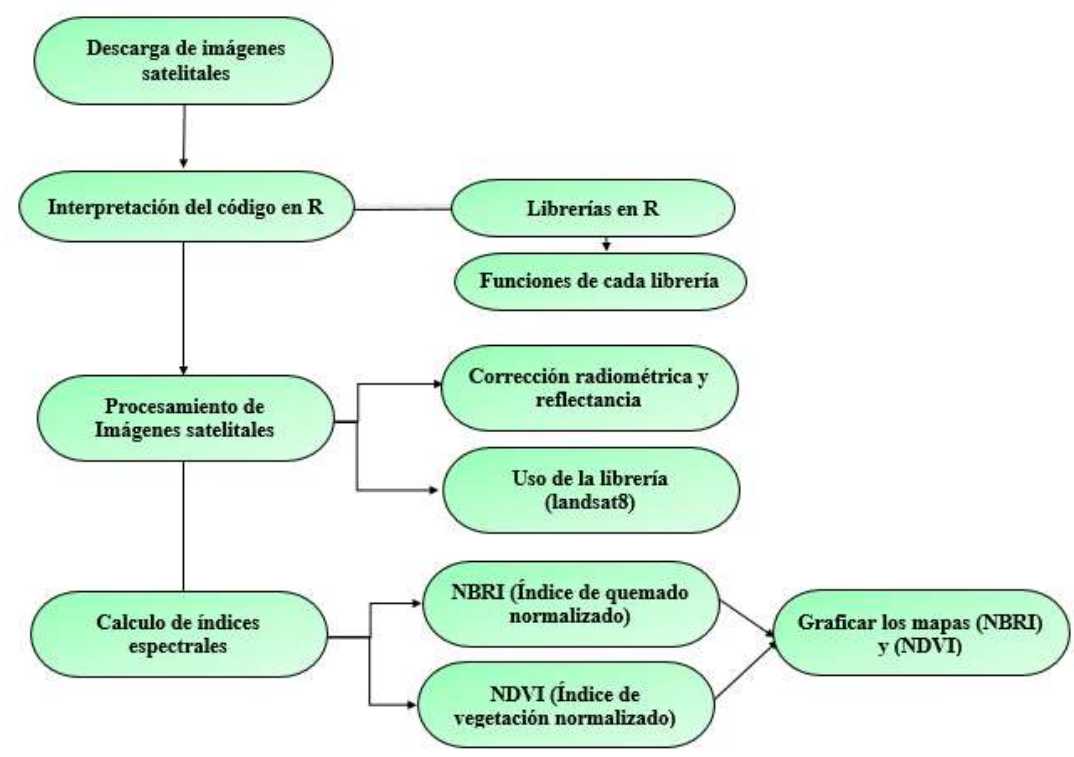

Figura 1. Diagrama de flujo del procesamiento de imágenes satelitales Landsat 8 Oli.

\section{Índices espectrales}

Los índices espectrales fueron calculados con el paquete RStoolbox del software R, que concede funciones eficaces para el análisis de datos de teledetección, como el pre procesamiento de imágenes de satélite, clasificación de uso y cobertura del suelo de forma supervisada y no supervisada, permite calcular los índices espectrales NDVI y NBRI, haciendo uso del infrarrojo cercano NIR y la capa de reflectancia roja automáticamente (Wegmann et al., 2020). Las zonas de color verde oscuro en el NDVI indican valores elevados del índice, mientras que en las áreas con menos vegetación o de suelo desnudo se visualizan en marrón claro, en las áreas de bosque los valores de NDVI son más altos que los ubicados en áreas agrícolas. Pese a esto, algunos campos también cuentan con valores NDVI muy altos; de tal manera que, nosotros no podemos deducir que los valores altos son siempre indicativos de cobertura forestal. Un valor alto de NDVI, indica que esta área tiene una densa cobertura vegetal fotosintéticamente activa.

\section{Imágenes satelitales}

Se utilizaron imágenes satelitales Landsat 8 (OLI) tomadas después del incendio forestal, lo más próximo al cierre de esta investigación, ubicada en el PATH= 10 y ROW 63. Estas imágenes fueron obtenidas del servidor del Servicio Geológico de Estados Unidos (USGS). En 


\section{AMAZÖNAS}

este estudio se utilizaron imágenes Landsat 8 debido a la resolución espacial de sus bandas espectrales y los beneficios que estas brindan para el estudio (Barsi et al., 2014). Comparado con otras imágenes satelitales anterior al Landsat 8 debido a misiones anteriores espaciales se pueden utilizar imágenes previas de otros sensores remotos.

\section{Evaluación de la severidad}

Se debe conocer los rangos interespecíficos para reconocer la salud de la vegetación. Estos rangos pueden ser interpretados mediante el procesamiento de la información espectral incluidas en la cartografía del área quemada (Bastarrika \& Chuvieco, 2006). Tanto las imágenes Landsat (Montellano, 2012), como los índices espectrales (Martínez et al., 2017) tienen diversas aplicaciones y cumplen diversas funciones. Para determinar los de mejor aplicabilidad, se realizó un análisis visual que comparo la resolución conociendo el área in situ de la afectación (Gómez et al., 2017).

\section{Resultados y discusión}

Los valores espectrales obtenidos permitieron inferir el daño en vegetación considerándose los valores 0.15 en los dos índices como vegetación con problemas, estos valores variaron mucho entre ellos especialmente con el índice NDVI el cual la nubosidad del área de estudio como un problema de la vegetación siendo una evaluación errónea (Figura 2.), pero no se pudo identificar con eficiencia el área donde se produjo el incendio forestal haciendo el uso de este índice espectral ineficiente para su aplicación, pero podría ser eficiente en la evaluación de su recuperación (Gómez-Sánchez et al., 2017). La posibilidad de realizar un mapeo de las zonas de afectación por fenómenos provocados por incendios forestales, es una herramienta esencial en la determinación del impacto o severidad de los mismos

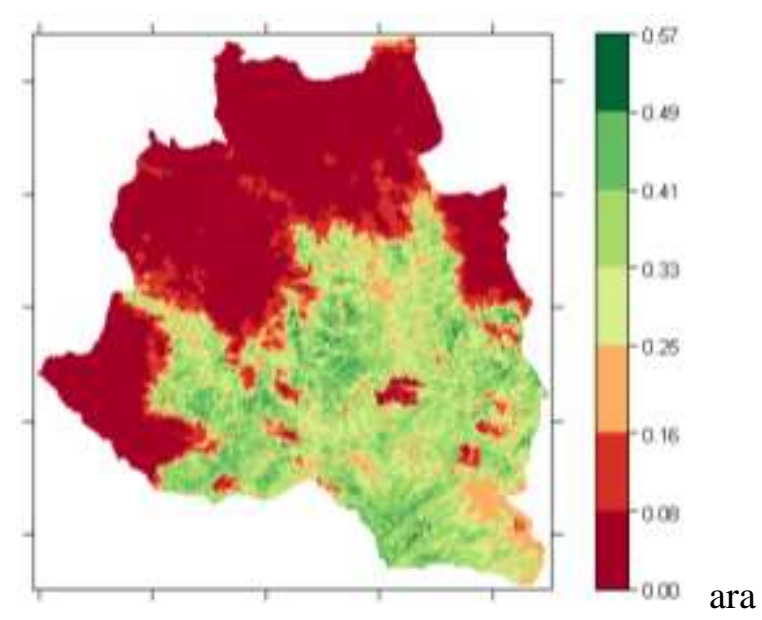

Figura 2. Imagen espectral del incendio forestal con el índice NDVI.

Sin embargo, utilizando el índice espectral NBRI se hizo una correcta identificación del incendio forestal, se evidencia como un incendio se puede extender rápidamente sobre un área, además que debido a la combinación de las bandas espectrales se puede identificar los cambios en la cobertura vegetal y discriminar la nubosidad que existía en el área de estudio (Figura 3.). 


\section{AMAZÖNAS}

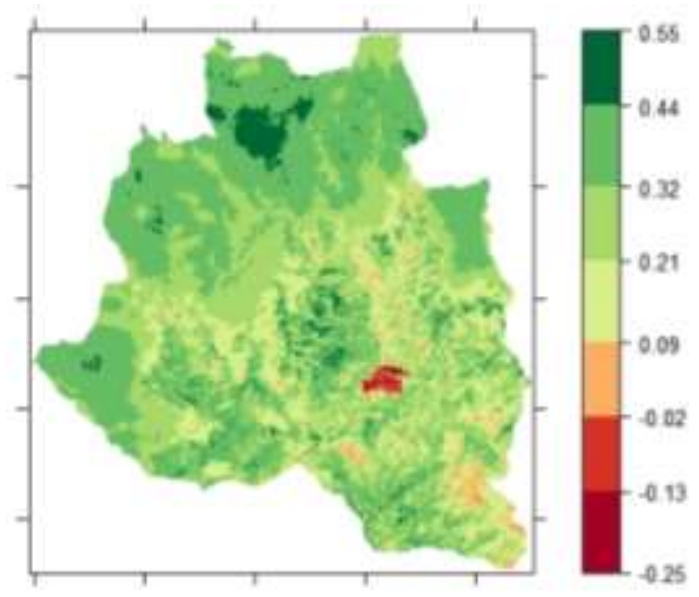

Figura 3. Imagen espectral del incendio forestal con el índice NBRI.

De acuerdo a la revisión bibliográfica realizada de las consecuencias que producen los incendios forestales en la biodiversidad de Ecuador, se encontraron algunos antecedentes, aunque no se han mencionado en los efectos en el cantón chilla de forma amplia a excepciones de los reportados por (Orellana \& Lalvay, 2018) en la que describe como la población se ve preocupada por la continua degradación de los recursos naturales debido a estos siniestros ya sean involuntarios o provocados (Castillo et al., 2003). Siendo un país que garantiza los derechos de la naturaleza con instrumentos que promuevan la restauración ecológica de los ecosistemas afectados no existen mecanismos que coadyuven el cumplimiento de sus derechos (González et al., 2017).

Uno de los principales factores que permiten la proliferación de incendios forestales en esta zona es su topografía, para lo cual se deben realizar el control de estos incendios, por medio de la ayuda de la población que viven cerca de donde se produce el siniestro produciendo un riesgo colateral para sus pobladores (Figura 4). Además, la vegetación seca en esta temporada del año permite las condiciones idóneas para la combustión, dificultando las actividades para realizar el control. Muchas de estas especies afectadas se dan en zonas muy alejadas a la población de acuerdo a estudios previos muchas de esta vegetación son silvestres y tiende a tener propiedades aprovechables y genes de resiliencia a el cambio climáticas.

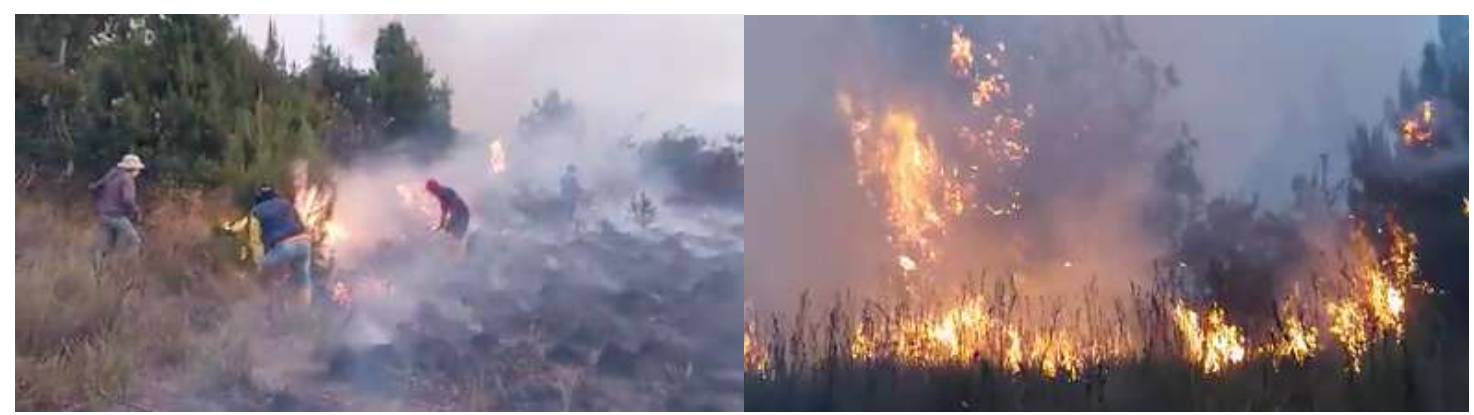

Figura 4. Consecuencias de los incendios forestales en la vegetación.

Cuando se suscita un incendio forestal, dependiendo de la localización del punto o foco de propagación del incendio este destruye por medio de los procesos de combustión todos los recursos naturales que le sirva como combustible, dañando así las especies forestales y los pastizales, especialmente cuando estos se encuentran atravesando época de sequía. Los daños más comunes en las zonas andinas se dan en especies forestales de las cuales debido a su ciclo de vida, se convierte en un daño económico al ser sembrados con fines de comercialización, y 
ambientalmente por la quema que genera la huella de carbono al ecosistema (Zapata \& Rascón, 2020). En los suelos donde se suscita un incendio forestal causa daños en las propiedades físicas químicas y biológicas, estas pueden variar de acuerdo a la intensidad con la que se produzca el daño (Bodí et al., 2012).

\section{Conclusiones}

El cantón Chilla es considerado uno de los cantones con alta heterogeneidad de su biodiversidad en la provincia del Oro, influenciada especialmente por los diferentes pisos altitudinales y latitudinales, afectada por los continuos daños a los recursos naturales producidos por los incendios forestales, para lo cual se hacen necesario conservar las especies in situ y ex situ y así evitar la degradación de los ecosistemas de estas zonas de alta biodiversidad, cuyos daños producidos se enfocan especialmente a la perdida de los habitas de las especies, degradación forestal, pastizales, agrobiodiversidad y de los suelos, y daños en la cobertura vegetal de la zona.

El riesgo que produce a la población recaen principalmente a la perdida de pastizales, cultivos, en otro caso llega afectar viviendas. Además de posibles siniestros que se puedan dar sobre sus pobladores al realizar actividades para el control de incendios y evitar la pérdida de sus cultivos o daños en los terrenos.

El Uso de herramientas de análisis espacial permiten tener una visión global del daño producido por un incendio forestal, monitorear esto es de vital importancia para proponer medidas de mitigación y reparación ambiental. De los índices espectrales aplicados en este estudio el NBRI demostró ser más eficiente con respecto al NDVI, para evaluar el momento donde se produjeron los incendios forestales, evaluar el daño producido en la cobertura vegetal desde una vista espacial, pero no se descarta su uso para evaluar la recuperación de la cobertura vegetal de zonas afectadas.

\section{Referentes Bibliográficas}

Barsi, J., Lee, K., Kvaran, G., Markham, B., \& Pedelty, J. (2014). The Spectral Response of the Landsat-8 Operational Land Imager. Remote Sensing, 6(10), 10232-10251. https://doi.org/10.3390/rs61010232

Bastarrika, A., \& Chuvieco, E. (2006). Cartografía del área quemada mediante crecimiento de regiones: aplicación en entornos mediterráneos con imágenes tm y etm+1. GeoFocus, 6 , 82-204.

Belduma, R. G. B., \& Barrezueta-Unda, C. S. (2018). Migración de agricultores del Cantón Chilla: un estudio de caso desde la preceptiva social y económica. Revista Científica Agroecosistemas, 6(3), 89-96.

Bodí, M. B., Cerdà, A., Mataix-Solera, J., \& Doerr, S. H. (2012). Efectos de los incendios forestales en la vegetación y el suelo en la cuenca mediterránea: revisión bibliográfica. Boletín de La Asociación de Geógrafos Españoles, 58, 33-56.

Castillo, M., Pedernera, P., \& Pena, E. (2003). Incendios forestales y medio ambiente: una síntesis global. Revista Ambiente y Desarrollo, 19(2), 44-53.

Chuvieco, E., Aguado, I., Salas, J., García, M., Yebra, M., \& Oliva, P. (2020). Satellite Remote Sensing Contributions to Wildland Fire Science and Management. Current Forestry Reports, 6(2), 81-96. https://doi.org/10.1007/s40725-020-00116-5

Flannigan, M., Stocks, B., \& Wotton, B. (2000). Climate change and forest fires. Science of The Total Environment, 262(3), 221-229. https://doi.org/10.1016/S0048-9697(00)00524-6

Gandrud, C. (2018). Reproducible Research with R and RStudio. Chapman and Hall/CRC. https://doi.org/10.1201/9781315382548

Gómez-Sánchez, E., De las Heras, J., Lucas-Borja, M., \& Moya, D. (2017). Ajuste de metodologías para evaluar severidad de quemado en zonas semiáridas (SE peninsular): 


\section{AMAZÖNAS}

incendio Donceles 2012. Revista de Teledetección, 49, 103. https://doi.org/10.4995/raet.2017.7121

Gómez, C., Hermosilla, T., Martínez-Fernández, J., Montes, F., Aulló-Maestro, I., White, J. C., Wulder, M. A., Coops, N. C., \& Vázquez, A. (2017). Cartografía anual de incendios forestales (1985-2015) en el Noroeste de España a partir de serie temporal de datos Landsat y algoritmo Composite2Change. Nuevas Plataformas y Sensores de Teledetección. XVII Congreso de La Asociación Española de Teledetección, 169-172.

González, J., Pambi, V., Uyaguari, E., \& Zhiñin, H. (2017). Estado actual de la restauración ecológica en la Región Sur del Ecuador. CEDAMAS, 7(1), 16-25.

Martínez, S., Chuvieco, E., Aguado, I., \& Salas, J. (2017). Burn severity and regeneration in large forest fires: an analysis from Landsat time series. Revista de Teledetección, 49, 17. https://doi.org/10.4995/raet.2017.7182

Matailo-Ramirez, L. M., Luna-Romero, Á. E., Alava, A. R. C., \& Jaramillo, F. Y. V. (2019). Sequías: efecto sobre los recursos naturales y el desarrollo sostenible. Revista Científica Agroecosistemas, 7(3), 154-162.

Montellano, A. R. (2012). Cartografía multitemporal de quemas e incendios forestales en Bolivia: Detección y validación post-incendio. Ecología En Bolivia, 47(1), 53-71.

Orellana, J. A., \& Lalvay, T. D. C. (2018). Uso e importancia de los recursos naturales y su incidencia en el desarrollo turístico. Caso Cantón Chilla, El Oro, Ecuador. Revista Interamericana de Ambiente y Turismo, 14(1), 65-79. https://doi.org/10.4067/S0718235X2018000100065

Parra-Lara, Á., \& Bernal-Toro, F. H. (2010). Incendios de cobertura vegetal y biodiversidad: una mirada a los impactos y efectos ecológicos potenciales sobre la diversidad vegetal. El Hombre y La Máquina, 35, 67-81.

Pazmiño, D. (2019). Peligro de incendios forestales asociado a factores climáticos en Ecuador. FIGEMPA: Investigación y Desarrollo, 1(1), 10-18. https://doi.org/10.29166/revfig.v1i1.1800

Rodríguez, M. P. R., Rodríguez, Y. C., Sierra, C. A. M., Batista, A. C., \& Tetto, A. F. (2017). Relación entre variables meteorológicas e incendios forestales en la provincia de Pinar del Río, Cuba. FLORESTA, 47(3). https://doi.org/10.5380/rf.v47i3.50900

Vidal, C., Velepucha, L., Tur, M., \& Samaniego, E. (2015). Plan de desarrollo y ordenamiento territorial de Chilla. Gobierno Autónomo Descentralizado del Cantón Chilla.

Vidal, L., Useche, D. \& Hernández, S. (2013). Biodiversidad y el cambio antrópico del clima: ejes temáticos que orientan la generación. Ambiente y Desarrollo, 17(32), 79-96.

Wegmann, M., Schwalb-Willmann, J., \& Dech, S. (2020). An Introduction to Spatial Data Analysis: Remote Sensing and GIS with Open Source Software. Pelagic Publishing.

Zapata, H. M. M., \& Rascón, J. (2020). La atipicidad legal medioambiental y el daño a los recursos naturales: El caso de los incendios forestales ocurridos en Chachapoyas y Luya, Perú. Arnaldoa, 27(1), 202-208. http://dx.doi.org/10.22497/arnaldoa.271.27122

Zhiminaicela-Cabrera, J. B., Quevedo-Guerrero, J. N., León-Salto, M. B., \& Mora-Encalada, C. P. (2020a). Algoritmo semi automático para mapear incendios forestales y estimar la recuperación vegetal mediante imágenes Landsat-8. Revista Tecnológica ESPOL, 32(2).

Zhiminaicela-Cabrera, J. B., Quevedo-Guerrero, J. N., Herrera Reyes, S. N., Sánchez Quinche, A. R., \& Bermeo-Gualan, L. Y. (2020b). Estudio etnobotánico de plantas medicinales e importancia de conservar las especies vegetales silvestres del cantón chilla, Ecuador. Ethnoscientia, 5(1). https://doi.org/10.22276/ethnoscientia.v5i1.332 